\title{
Produção, decomposição e ciclagem de nutrientes em resíduos de crotalária e milheto, cultivados solteiros e consorciados
}

\author{
Rogério Peres Soratto(1), Carlos Alexandre Costa Crusciol(1), Claudio Hideo Martins da Costa(1), \\ Jayme Ferrari Neto(1) e Gustavo Spadotti Amaral Castro(2)
}

\begin{abstract}
(1)Universidade Estadual Paulista, Faculdade de Ciências Agronômicas, Campus de Botucatu, Caixa Postal 237, CEP 18603-970 Botucatu, SP. E-mail: soratto@fca.unesp.br, crusciol@fca.unesp.br, c_hideo@hotmail.com, jaymeferrari@hotmail.com (2)Embrapa Amapá, Rodovia Juscelino Kubitschek, Km 5, Caixa Postal 10, CEP 68903-419 Macapá, AP. E-mail: gustavo.castro@embrapa.br
\end{abstract}

Resumo - O objetivo deste trabalho foi avaliar a produção de fitomassa e as taxas de decomposição e liberação de macronutrientes e de silício, nos resíduos vegetais de crotalária (Crotalaria juncea) e milheto (Pennisetum glaucum), em cultivo solteiro e consorciado. Utilizou-se o delineamento em blocos ao acaso, com quatro repetições, em arranjo fatorial constituído por três tipos de cobertura vegetal - milheto, crotalária e consórcio entre as espécies - e seis épocas de coleta - 0, 18, 32, 46, 74 e 91 dias após o manejo (DAM). O milheto apresenta maior produção de matéria seca e acumula mais $\mathrm{N}, \mathrm{P}, \mathrm{K}, \mathrm{Mg}, \mathrm{S}, \mathrm{C}$ e Si, enquanto a crotalária acumula maior quantidade de $\mathrm{Ca}$. A fitomassa do milheto apresenta as maiores taxas de decomposição e de liberação de nutrientes. Essas taxas são mais intensas entre 0 e 18 DAM. Com o transcorrer do tempo, as relações C/N, $\mathrm{C} / \mathrm{P}$ e C/S aumentam e a relação $\mathrm{C} / \mathrm{Si}$, bem como a taxa de decomposição da fitomassa, diminui. O potássio é o nutriente de liberação mais rápida, e o silício apresenta a menor taxa de liberação.

Termos para indexação: Crotalaria juncea, Pennisetum glaucum, fitólitos, meia-vida, relação C/N, taxa de decomposição.

\section{Production, decomposition and nutrient cycling in residues of sunnhemp and pearl millet in monocropped and intercropped systems}

\begin{abstract}
The objective of this work was to evaluate the biomass production and the rates of decomposition and macronutrient and silicon release on crop residues of sunnhemp (Crotalaria juncea) and pearl millet (Pennisetum glaucum), in monocropped and intercropped systems. A randomized complete block design was used, with four replicates in a factorial arrangement consisting of three cover crops - pearl millet, sunnhemp, and these species intercropped - and six sampling times - 0, 18, 32, 46, 74, and 91 days after management (DAM). Pearl millet produces a greater amount of dry matter and accumulates more N, P, K, Mg, S, C, and Si, whereas sunnhemp accumulates more $\mathrm{Ca}$. Pearl millet phytomass has the highest rates of decomposition and nutrient release. These rates are higher between 0 and 18 DAM. Over the time, the $\mathrm{C} / \mathrm{N}, \mathrm{C} / \mathrm{P}$ and $\mathrm{C} / \mathrm{S}$ ratios increase, and the $\mathrm{C} / \mathrm{Si}$ ratio, as well as the decomposition rate, decreases. Potassium is the most rapidly released nutrient, and silicon has the lowest release rate.
\end{abstract}

Index terms: Crotalaria juncea, Pennisetum glaucum, phytoliths, half-life, $\mathrm{C} / \mathrm{N}$ ratio, decomposition rate.

\section{Introdução}

Para a sustentabilidade do sistema plantio direto, especialmente nas regiões tropicais, é indispensável que a palhada seja mantida sobre a superfície do solo de forma permanente. Contudo, em regiões tropicais, o inverno quente e seco e o verão quente e chuvoso limitam o cultivo de culturas anuais, na entressafra, e aceleram a decomposição da cobertura vegetal do solo (Pacheco et al., 2011a, 2011b). Nessas condições de clima, as características mais importantes nas plantas de cobertura do solo são a quantidade e a durabilidade da fitomassa produzida (Boer et al., 2008; Leite et al., 2010), bem como a sua capacidade de ciclagem de nutrientes, principalmente para os livixiados em profundidade ou os pouco solúveis. É interessante, também, que os nutrientes sejam liberados dos resíduos de forma gradativa, para a cultura subsequente (Crusciol et al., 2008).

Os efeitos benéficos das plantas de cobertura foram observados por vários autores, seja nas propriedades químicas e físicas do solo, seja na produtividade dos

Pesq. agropec. bras., Brasília, v.47, n.10, p.1462-1470, out. 2012 
cultivos em sucessão (Gama-Rodrigues et al., 2007; Crusciol \& Soratto, 2007, 2009; Pacheco et al., 2011a, 2011b).

O milheto [Pennisetum glaucum (L.) R. Brown] e a crotalária (Crotalaria juncea L.) são espécies bastante utilizadas como plantas de cobertura. A primeira caracteriza-se por rápido crescimento e estabelecimento no campo, mesmo em condições de estresse hídrico; elevada produção e persistência da palhada sobre o solo, que pode ultrapassar $14 \mathrm{Mg} \mathrm{ha}^{-1}$; e alta capacidade de extração de nutrientes, com alta eficiência na ciclagem de $\mathrm{N}$ e $\mathrm{K}$, que podem atingirvalores de 205 e $215 \mathrm{kgha}^{-1}$, respectivamente (Crusciol \& Soratto, 2009). Já a crotalária, apresenta boa produção de fitomassa, superior a $8 \mathrm{Mg} \mathrm{ha}^{-1}$ (Menezes et al., 2009), serve como adubo verde, com fixação de $\mathrm{N}_{2}$ atmosférico que pode chegar a $150-165 \mathrm{~kg} \mathrm{ha}^{-1}$ (Wutke, 1993), e tem ação antagônica sobre nematoides no solo (Inomoto et al., 2008). Entretanto, sua persistência no solo costuma ser comparativamente inferior à de gramíneas tropicais, como o milheto. Torres et al. (2008) relataram que a metade dos resíduos provenientes da crotalária foi decomposta aos 98 dias, enquanto os do milheto foram decompostos aos 131 dias.

Ao se considerar essas características, a consorciação entre essas duas espécies pode ser uma alternativa interessante para o sistema plantio direto, pois tem a possibilidade de fornecer fitomassa para cobertura do solo, de incrementar o conteúdo de nutrientes neste especialmente os de N e K (Perin et al., 2004; Teixeira et al., 2009) -, e pode contribuir para o controle de nematoides. Há diversos relatos sobre o cultivo solteiro dessas espécies; porém, são poucos os trabalhos que as avaliaram em cultivo consorciado. Desse modo, é essencial que se conheça a dinâmica de decomposição e de liberação de nutrientes da palhada em sistemas consorciados, como forma de argumento técnico para as recomendações de manejo desses sistemas, sobretudo em áreas com problemas com nematoides e em regiões com baixa produção ou persistência de palhada.

O objetivo deste trabalho foi avaliar a produção de fitomassa e as taxas de decomposição e liberação de macronutrientes e de silício, nos resíduos vegetais de crotalária e milheto, em cultivo solteiro e consorciado.

\section{Material e Métodos}

O trabalho foi desenvolvido em condições de campo, na Fazenda Experimental Lageado, da Faculdade de
Ciências Agronômicas da Unesp, em Botucatu, SP ( $22^{\circ} 58^{\prime} \mathrm{S}$ e $48^{\circ} 23^{\prime} \mathrm{W}$, a $765 \mathrm{~m}$ de altitude). O solo do local é classificado como Nitossolo Vermelho (Santos et al., 2006), e o clima predominante na região, de acordo com Köppen, é do tipo Cwa, tropical de altitude, com inverno seco e verão quente e chuvoso.

Os dados referentes à temperatura média e à precipitação mensal durante o período de condução do experimento são apresentados na Figura 1.

As características químicas do solo $(0-20 \mathrm{~cm})$ foram determinadas antes da instalação do experimento, com os seguintes resultados: $25 \mathrm{~g} \mathrm{dm}^{-3}$ de matéria orgânica, $\mathrm{pH}\left(\mathrm{CaCl}_{2}\right) 5,0,17 \mathrm{mg} \mathrm{dm}{ }^{-3}$ de $\mathrm{P}$ (resina), 1,6, 33,3, 17,6 e 34,1 mmol $_{\mathrm{c}} \mathrm{dm}^{-3}$ de K, Ca, Mg e H+Al, respectivamente, e $61 \%$ de saturação por bases. O solo apresenta textura argilosa, com $512 \mathrm{~g} \mathrm{~kg}^{-1}$ de argila, $381 \mathrm{~g} \mathrm{~kg}^{-1}$ de areia e $107 \mathrm{~g} \mathrm{~kg}^{-1}$ de silte.

Utilizou-se o delineamento experimental de blocos ao acaso, com quatro repetições, em arranjo fatorial $3 \times 6$, constituído por três coberturas vegetais - milheto, crotalária e consórcio milheto + crotalária) - e seis épocas de coleta da fitomassa - 0, 18, 32, 46, 74 e 91 dias após o manejo (DAM). As parcelas apresentavam $5 \mathrm{~m}$ de largura e $15 \mathrm{~m}$ de comprimento, em um total de $75 \mathrm{~m}^{2}$.

Antes da semeadura das espécies, foi realizada a dessecação das plantas presentes na área com a utilização do herbicida glifosato (1.920 $\mathrm{g} \mathrm{ha}^{-1}$ do i.a.). A semeadura das espécies de cobertura foi realizada em 21/10/2004, e a emergência ocorreu nove dias depois (30/10/2004). Utilizaram-se $40 \mathrm{~kg} \mathrm{ha}^{-1}$ de sementes de crotalária ('IAC-KR1'), 20 de milheto ('BN-2') e 20+10 de crotalária + milheto, no espaçamento de $0,17 \mathrm{~m}$ entre linhas, aproximadamente, a $0,03 \mathrm{~m}$ de profundidade. Não foi realizado nenhum trato cultural,

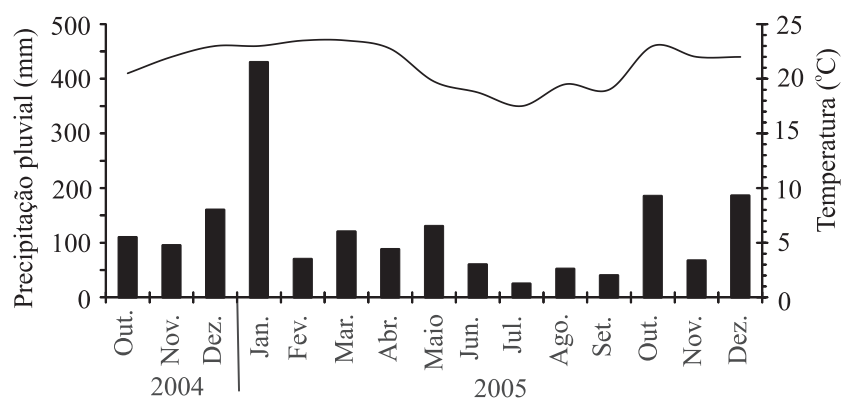

Figura 1. Precipitação mensal (U) e temperatura média mensal (-) no período de condução do experimento. 
como adubação, controle de plantas daninhas, pragas e doenças.

No momento do florescimento das espécies, aos 75 dias após a emergência (DAE), em 14/1/2005, foi realizado o manejo químico com a utilização do herbicida glifosato (1.920 $\mathrm{g} \mathrm{ha}^{-1}$ do i.a.).

Foram realizadas coletas da cobertura vegetal no dia da dessecação (0 DAM), em 1/2/2005 (18 DAM), em 15/2/2005 (32 DAM), em 1/3/2005 (46 DAM), em 29/3/2005 (74 DAM) e em 15/4/2005 (91 DAM). Em cada época de coleta, foram amostrados três esquadros com $0,25 \mathrm{~m}^{2}$ de área interna, conforme Crusciol et al. (2005). Essas três amostras simples constituíram a amostra composta, representante de cada parcela. A amostragem, dentro das unidades experimentais, foi realizada no sentido diagonal da parcela, tendo-se escolhido, de forma aleatória, os pontos de coleta, e excluído $0,50 \mathrm{~m}$ de cada extremidade, a título de bordadura.

Os resíduos vegetais sofreram pré-limpeza, para a remoção das partículas maiores de solo, e, em seguida, foram lavados sem o emprego de detergente, com agitação em água deionizada por alguns segundos, em três porções sucessivas. Após a lavagem, as amostras foram depositadas sobre papel absorvente. A não utilização de detergente diminui o tempo de exposição à agitação com água e o número de porções sucessivas, o que reduz, ao máximo, as prováveis perdas de $\mathrm{K}$ da fitomassa. As amostras foram acondicionadas em sacos de papel, secadas em estufa com circulação forçada de ar, a $65^{\circ} \mathrm{C}$, até atingirem massa constante, e pesadas, para determinação da fitomassa seca. Em seguida, o material foi moído em moinho tipo Willey, para posterior determinação dos teores de macronutrientes (Malavolta et al., 1997), carbono (Tedesco et al., 1985) e silício (Korndörfer et al., 2002).

As quantidades de macronutrientes, $\mathrm{C}$ e $\mathrm{Si}$ remanescentes na fitomassa foram determinadas pelo produto da quantidade de fitomassa seca e os teores dos elementos no resíduo vegetal. De posse desses valores, calculou-se a liberação de nutrientes para o solo, tendo-se subtraído a quantidade remanescente pela quantidade inicial dos macronutrientes, $\mathrm{C}$ e Si.

Para descrever a decomposição da fitomassa e a liberação dos nutrientes (N, P, K, Ca, Mg, S e C), utilizou-se o modelo matemático exponencial descrito por Thomas \& Asakawa (1993), do tipo X $=\mathrm{Xoe}^{-\mathrm{kt}}$, em que $X$ é a quantidade de matéria seca remanescente após um período de tempo t, em dias; Xo é a quantidade inicial de matéria seca ou de nutriente; e k é a constante de decomposição do resíduo. Com o valor de $\mathrm{k}$, foi calculado o tempo de meia-vida $\left(\mathrm{T}^{1} / 2=0,693 / \mathrm{k}\right)$ (Paul \& Clark, 1989), que expressa o período de tempo necessário para que metade dos resíduos decomponhase ou para que metade dos nutrientes contidos nos resíduos seja liberada. Pela aplicação da derivada primeira às equações ajustadas aos dados de liberação acumulada de macronutrientes, calcularam-se as taxas diárias de decomposição da fitomassa e de liberação dos nutrientes após o manejo (Rosolem et al., 2003; Kliemann et al., 2006).

Os dados foram submetidos ao teste de normalidade de Lillifors e de homogeneidade de Cochran \& Bartlett, para verificar o atendimento dos requisitos para o emprego da análise de variância. Os tipos de cobertura vegetal foram comparados pelo teste de Tukey, a $5 \%$ de probabilidade, e os dados relativos às épocas de coletas foram ajustados a equações de regressão, com teste de significância a 5\% de probabilidade.

\section{Resultados e Discussão}

O milheto, no momento da dessecação, produziu a maior quantidade de fitomassa seca, em comparação às demais coberturas vegetais, com produtividade média de 14,04 $\mathrm{Mg} \mathrm{ha}^{-1}$ de matéria seca (MS). Este resultado deveu-se, principalmente, ao rápido crescimento inicial da espécie (Figura 2). Crusciol \& Soratto (2009) verificaram produção de matéria seca de milheto muito semelhante $\left(14,8 \mathrm{Mg} \mathrm{ha}^{-1}\right)$, na mesma região. As produtividades da crotalária $\left(8,11 \mathrm{Mg} \mathrm{ha}^{-1}\right.$ de MS $) \mathrm{e}$ do consórcio $\left(8,47 \mathrm{Mg} \mathrm{ha}^{-1}\right)$ foram similares entre si, e próximas às observadas por Menezes et al. (2009), que obtiveram valores de $8,69 \mathrm{Mg} \mathrm{ha}^{-1}$, para a crotalária, e de $9,18 \mathrm{Mg} \mathrm{ha}^{-1}$, para o consórcio crotalária + milheto. Esses autores realizaram seu experimento em condições edafoclimáticas semelhantes às do presente trabalho, com semeadura realizada em 20 de setembro e manejo aos 90 DAE, em Latossolo Vermelho distroférrico.

As maiores taxas de decomposição da fitomassa ocorreram no período de 0 a 18 DAM, tendo atingindo valores de 240, 76 e $93 \mathrm{~kg} \mathrm{ha}^{-1}$ por dia de MS, no milheto, na crotalária e no consórcio, respectivamente (Tabela 1). Esses resultados podem ser atribuídos à elevada temperatura média e à ocorrência de precipitação $\operatorname{logo}$ após o manejo (Figura 1), que 
aceleram a decomposição dos resíduos vegetais (Boer et al., 2008; Leite et al., 2010). A fitomassa do milheto atingiu 50\% da quantidade inicial aos 33 DAM, a da crotalária aos 65 DAM e a do consórcio aos 65 DAM (Figura $2 \mathrm{~A}$ ). Esses resultados são contrastantes aos de Torres et al. (2008), que observaram tempo de meia-vida de 98 e 131 dias, para fitomassa de crotalária e milheto, respectivamente. No entanto, o manejo adotado nos dois trabalhos foi diferente. Torres et al. (2008) seccionaram a fitomassa em fragmentos de $5 \mathrm{~cm}$ e, no presente trabalho, realizou-se apenas a dessecação química, sem seccionamento da fitomassa.

As relações $\mathrm{C} / \mathrm{N}, \mathrm{C} / \mathrm{P}$ e $\mathrm{C} / \mathrm{S}$ podem ser utilizadas para avaliação da resistência da fitomassa à decomposição. No momento do manejo, os valores de $\mathrm{C} / \mathrm{N}, \mathrm{C} / \mathrm{P}, \mathrm{C} / \mathrm{S}$ e C/Si eram, respectivamente, de $25,176,187$ e 16 no milheto, de 21, 207, 282 e 29 na crotalária, e de 25, 187 , 244 e 25 no consórcio (Figura 2). Boer et al. (2007) constataram valores próximos de $\mathrm{C} / \mathrm{N}$ para milheto $(25,3)$ e crotalária $(18,1)$, em cultivo solteiro.

Com o passar do tempo, as relações $\mathrm{C} / \mathrm{N}, \mathrm{C} / \mathrm{P}$ e $\mathrm{C} / \mathrm{S}$ aumentaram e a $\mathrm{C} / \mathrm{Si}$ diminuiu. A fitomassa remanescente de milheto, na última coleta (91 DAM), tinha grande concentração de Si (Figura 3): cerca de $8,4 \%$, aproximadamente 2,3 vezes a média dos demais tratamentos. Esse tecido remanescente pode ser considerado altamente silicificado, com elevado conteúdo de fitólitos, o que o tornaria de difícil degradação. Esses fitólitos se formam pela polimerização do $\mathrm{Si}$ absorvido pela planta e se
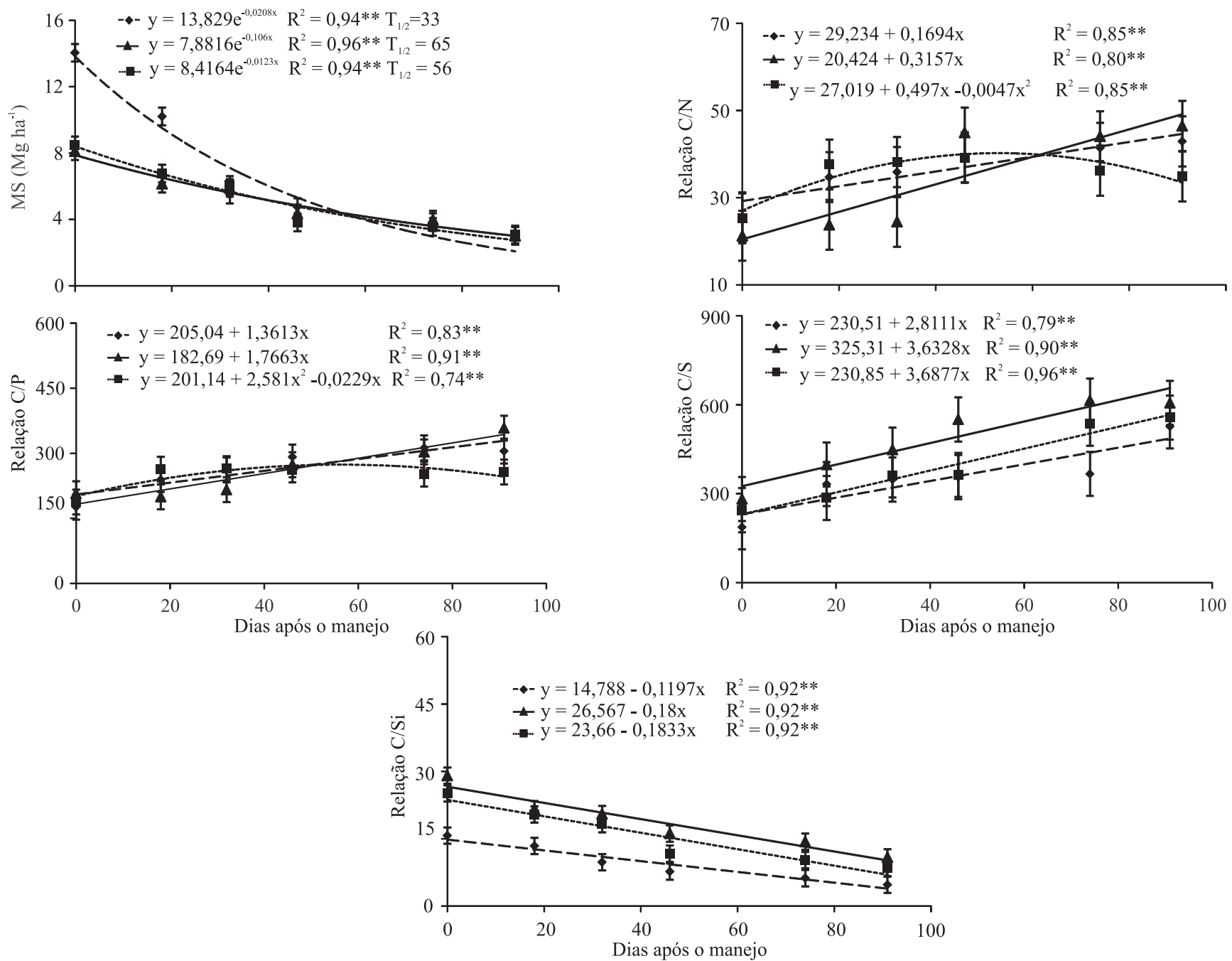

Figura 2. Produção de matéria seca e relações C/N, C/P, C/S e C/Si em milheto $\bullet-)$, crotalária ( $\bullet$ ) e no consórcio ( $\square \cdot)$, em função do tempo após o manejo. **Significativo a $1 \%$ de probabilidade pelo teste $\mathrm{F}$. $\mathrm{T}_{1 / 2}$, tempo de meia vida, em dias após o manejo. Barras verticais indicam o valor de DMS pelo teste de Tukey, a 5\% de probabilidade. 
acumulam tanto no entorno como dentro das células (Pinilla, 1997). Fernandez et al. (2009), entretanto, ao trabalhar com aplicação de silicato de cálcio em espécies de cobertura, relataram que as maiores concentrações de Si na fitomassa não aumentaram a persistência desta sobre a superfície do solo. Contudo, estudos que relacionam o Si com a persistência de fitomassa sobre a superfície do solo ainda são escassos.

Com relação aos teores dos macronutrientes e de $\mathrm{Si}$ e C na fitomassa, logo após a dessecação, constataram-

Tabela 1. Taxas de decomposição da matéria seca e de liberações diárias de N, P, K, Ca, Mg, S, C e Si da fitomassa ( $\mathrm{kg} \mathrm{ha}^{-1}$ por dia) de milheto, crotalária e do consórcio nos períodos de avaliação.

\begin{tabular}{|c|c|c|c|c|c|}
\hline \multirow[t]{2}{*}{ Cobertura } & \multicolumn{5}{|c|}{ Dias após o manejo } \\
\hline & $0-18$ & $19-32$ & $33-46$ & $47-74$ & $75-91$ \\
\hline & \multicolumn{5}{|c|}{ Matéria seca } \\
\hline Milheto & 240 & 172 & 128 & 84 & 52 \\
\hline Crotalária & 76 & 64 & 55 & 44 & 35 \\
\hline \multirow[t]{2}{*}{ Consórcio } & 93 & 76 & 64 & 50 & 38 \\
\hline & \multicolumn{5}{|c|}{ Nitrogênio } \\
\hline Milheto & 6,49 & 3,73 & 2,31 & 1,16 & 0,52 \\
\hline Crotalária & 3,43 & 2,38 & 1,74 & 1,10 & 0,66 \\
\hline \multirow[t]{2}{*}{ Consórcio } & 2,85 & 1,97 & 1,43 & 0,89 & 0,53 \\
\hline & \multicolumn{5}{|c|}{ Fósforo } \\
\hline Milheto & 1,03 & 0,56 & 0,34 & 0,16 & 0,07 \\
\hline Crotalária & 0,28 & 0,21 & 0,17 & 0,12 & 0,08 \\
\hline \multirow[t]{2}{*}{ Consórcio } & 0,36 & 0,25 & 0,19 & 0,12 & 0,08 \\
\hline & \multicolumn{5}{|c|}{ Potássio } \\
\hline Milheto & 14,19 & 3,33 & 0,97 & 0,18 & 0,02 \\
\hline Crotalária & 2,73 & 1,58 & 0,99 & 0,50 & 0,23 \\
\hline \multirow[t]{2}{*}{ Consórcio } & 4,29 & 1,99 & 1,03 & 0,40 & 0,13 \\
\hline & \multicolumn{5}{|c|}{ Cálcio } \\
\hline Milheto & 1,21 & 0,79 & 0,54 & 0,31 & 0,17 \\
\hline Crotalária & 1,60 & 1,02 & 0,69 & 0,39 & 0,20 \\
\hline \multirow[t]{2}{*}{ Consórcio } & 0,80 & 0,56 & 0,41 & 0,26 & 0,16 \\
\hline & \multicolumn{5}{|c|}{ Magnésio } \\
\hline Milheto & 0,88 & 0,59 & 0,41 & 0,25 & 0,14 \\
\hline Crotalária & 0,34 & 0,24 & 0,18 & 0,12 & 0,07 \\
\hline \multirow[t]{2}{*}{ Consórcio } & 0,34 & 0,25 & 0,20 & 0,14 & 0,09 \\
\hline & \multicolumn{5}{|c|}{ Enxofre } \\
\hline Milheto & 1,06 & 0,51 & 0,27 & 0,11 & 0,04 \\
\hline Crotalária & 0,33 & 0,22 & 0,16 & 0,10 & 0,05 \\
\hline \multirow[t]{2}{*}{ Consórcio } & 0,27 & 0,18 & 0,13 & 0,07 & 0,04 \\
\hline & \multicolumn{5}{|c|}{ Carbono } \\
\hline Milheto & 120 & 83 & 60 & 38 & 22 \\
\hline Crotalária & 53 & 42 & 34 & 25 & 18 \\
\hline \multirow[t]{2}{*}{ Consórcio } & 42 & 34 & 29 & 22 & 17 \\
\hline & \multicolumn{5}{|c|}{ Silício } \\
\hline Milheto & 4,70 & 3,36 & 2,18 & 0,42 & 0,00 \\
\hline Crotalária & 0,23 & 0,23 & 0,23 & 0,23 & 0,23 \\
\hline Consórcio & 0,21 & 0,21 & 0,21 & 0,21 & 0,21 \\
\hline
\end{tabular}

se maiores teores de $\mathrm{N}$ e Ca na crotalária, e de $\mathrm{K}, \mathrm{Mg}$, $\mathrm{S}$ e Si no milheto (Figura 3). Quanto ao consórcio, os teores de $\mathrm{K}, \mathrm{Ca}, \mathrm{Mg}$ e $\mathrm{S}$ estiveram em uma faixa intermediária, em relação às fitomassas dos cultivos solteiros. $\mathrm{O}$ maior teor de $\mathrm{N}$ na fitomassa da crotalária é explicado pela fixação biológica de nitrogênio (Perin et al., 2003). Já para o milheto, os maiores teores observados de $\mathrm{K}, \mathrm{Mg}$, S e Si, em sua fitomassa, são decorrentes de seu elevado potencial de ciclagem de nutrientes, já que essa espécie tem um sistema radicular muito profundo, que pode extrair nutrientes de camadas subsuperficiais do solo (Salton \& Kichel, 1998).

Verificou-se redução gradual nos teores de todos os macronutrientes e aumento no teor de Si da fitomassa remanescente (Figura 3). As taxas de liberação de nutrientes estão estreitamente relacionadas à alocação destes nas células e nos tecidos vegetais, de forma que os elementos mais solúveis são liberados primeiro do que os com menor solubilidade, como o Si (Fernandez et al., 2009). O K foi o nutriente liberado mais rapidamente no início, com posterior redução na taxa de liberação, provavelmente em função da baixa quantidade de $\mathrm{K}$ remanescente no tecido vegetal (Figuras 3 e 4 ). A rápida taxa de liberação inicial do elemento está de acordo com Perin et al. (2010), que estudaram as mesmas espécies vegetais avaliadas no presente trabalho. A rápida liberação inicial de $\mathrm{K}$ decorre do fato de esse elemento não estar associado a nenhum componente estrutural do tecido vegetal (Marschner, 2012). O K forma ligações de fácil reversibilidade com complexos orgânicos (Rosolem et al., 2003). Assim, à medida que a parte aérea das plantas inicia o processo de secagem e degradação, após o rompimento das membranas plasmáticas (Malavolta et al., 1997), a concentração desse nutriente, no tecido, diminui drasticamente, o que é intensificado pela água das chuvas (Khatounian, 1999). Portanto, as chuvas ocorridas após o manejo das espécies vegetais (Figura 1) contribuíram para a intensa liberação de $\mathrm{K}$ observada.

Quanto ao Si, o aumento dos teores na fitomassa remanescente, ao longo das amostragens, de 201\% para o milheto, $94 \%$ para crotalária e $115 \%$ para o consórcio, aos 91 DAM, em comparação aos valores iniciais (Figura 3), provavelmente ocorreu pelo aumento da concentração de fitólitos à medida que a fitomassa era degradada.

Por ocasião do manejo, o milheto destacou-se por acumular as maiores quantidades de $\mathrm{N}, \mathrm{P}, \mathrm{K}, \mathrm{Mg}, \mathrm{S}, \mathrm{C}$ 
e $\mathrm{Si}$, enquanto a crotalária apresentou maior acúmulo de $\mathrm{Ca}$ (Figura 4). O milheto, por ser uma espécie de crescimento rápido e ciclo curto, é capaz de extrair quantidades consideráveis de nutrientes em um curto espaço de tempo, principalmente de $\mathrm{N}$ e K (Crusciol \& Soratto, 2009). Já o consórcio entre as espécies avaliadas, de modo geral, acumulou quantidades intermediárias quando comparadas às do cultivo solteiro. $\mathrm{O}$ consórcio e o cultivo solteiro de crotalária também acumularam quantidades expressivas dos nutrientes.
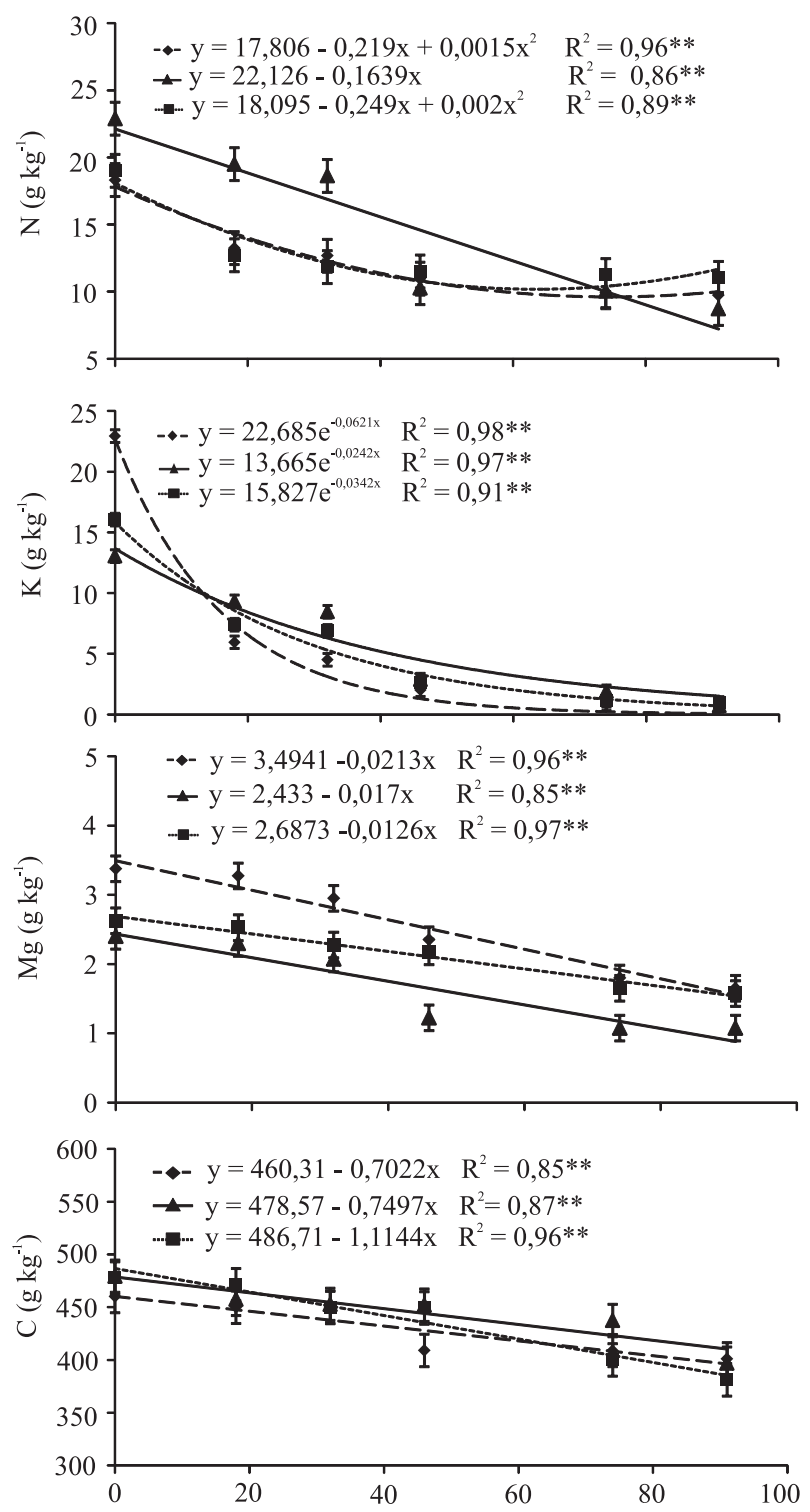

As quantidades acumuladas de $\mathrm{N}, \mathrm{P}, \mathrm{K}, \mathrm{Ca}, \mathrm{Mg}$, $\mathrm{S}, \mathrm{C}$ e Si foram de 257, 38, 322, 57, 47, 35, 6.459 e $412 \mathrm{~kg} \mathrm{ha}^{-1}$ no milheto, 184, 19, 107, 71, 20, 14, 3.906 e $135 \mathrm{~kg} \mathrm{ha}^{-1}$ na crotalária, e $161,22,136,46,22,17$, 4.041 e $162 \mathrm{~kg} \mathrm{ha}^{-1}$ no consórcio (Figura 4). Na última avaliação, restaram 11,3, 1,29, 0,1, 5,0, 4,5, 0,6, 798, 1.109 e $264 \mathrm{~kg} \mathrm{ha}^{-1}$ desses nutrientes na palhada de milheto, 23,9, 3,9, 5, 0, 5,7, 2,9, 1,3, 1.235 e $115 \mathrm{~kg} \mathrm{ha}^{-1}$ na de crotalária, e 18,9, 3,0, 1,8, 6,0, 4,5, 1,8, 1.068 e $141 \mathrm{~kg} \mathrm{ha}^{-1}$ na do consórcio. Dessa forma, na última
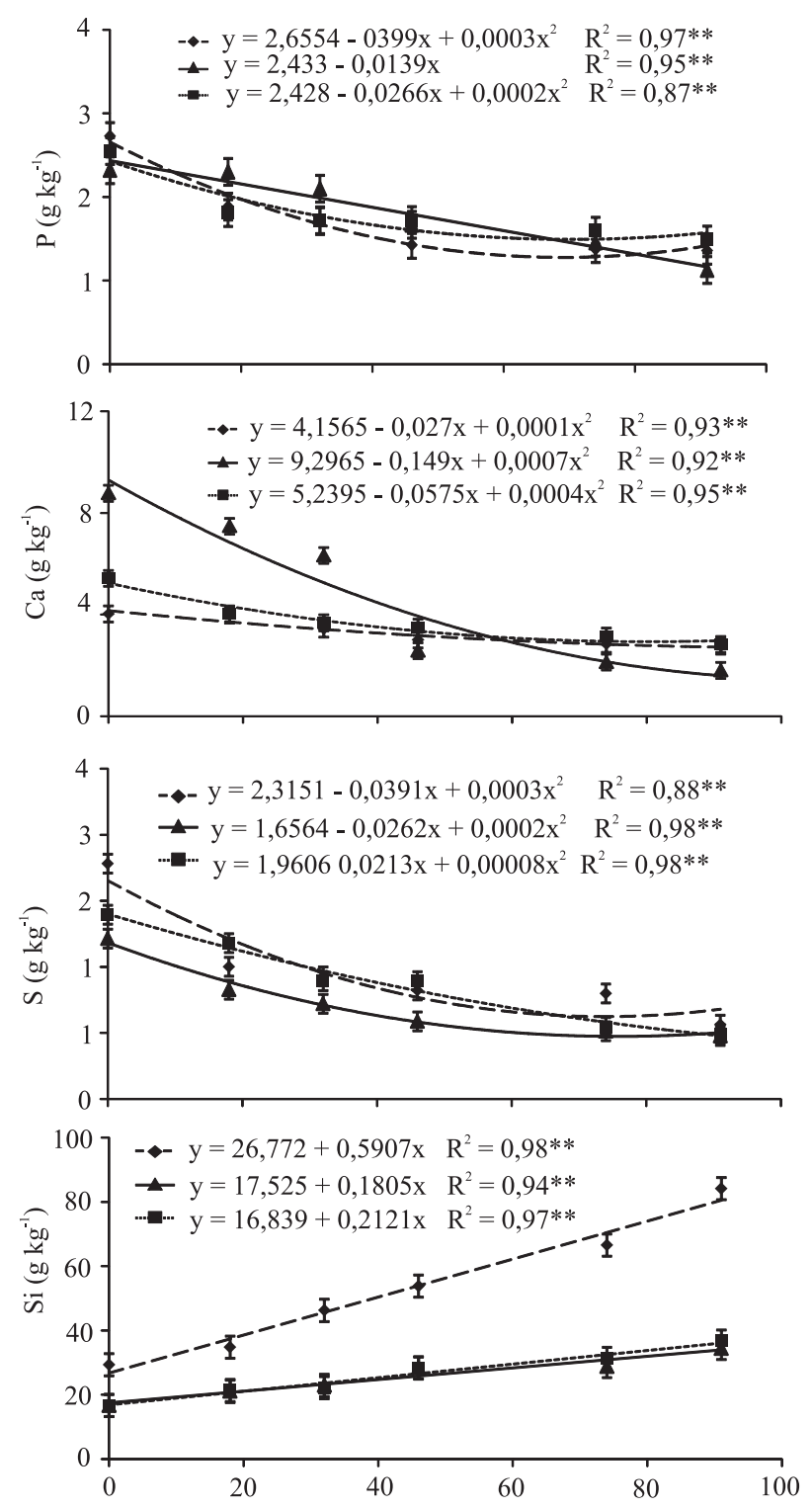

Dias após o manejo

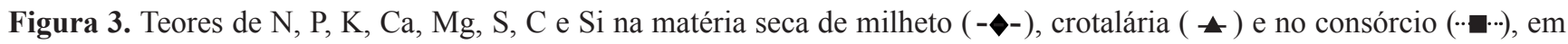
função do tempo após o manejo. **Significativo a $1 \%$ de probabilidade pelo teste F. Barras verticais indicam o valor de DMS pelo teste de Tukey, a 5\% de probabilidade. 
avaliação, haviam sido liberados $243,37,321,52,44$, $34,5.616$ e $264 \mathrm{~kg} \mathrm{ha}^{-1}$ pelo milheto, 161, 15, 103, 67, $17,12,2.548$ e $21 \mathrm{~kg} \mathrm{ha}^{-1}$ pela crotalária, e 133, 17, 133, $38,18,15,3.002$ e $19 \mathrm{~kg} \mathrm{ha}^{-1}$ pelo consórcio. Boer et al. (2007) também observaram, para o milheto, grandes quantidades de $\mathrm{N}, \mathrm{P}, \mathrm{K}, \mathrm{Ca}, \mathrm{Mg}$ e $\mathrm{S}$ disponibilizadas
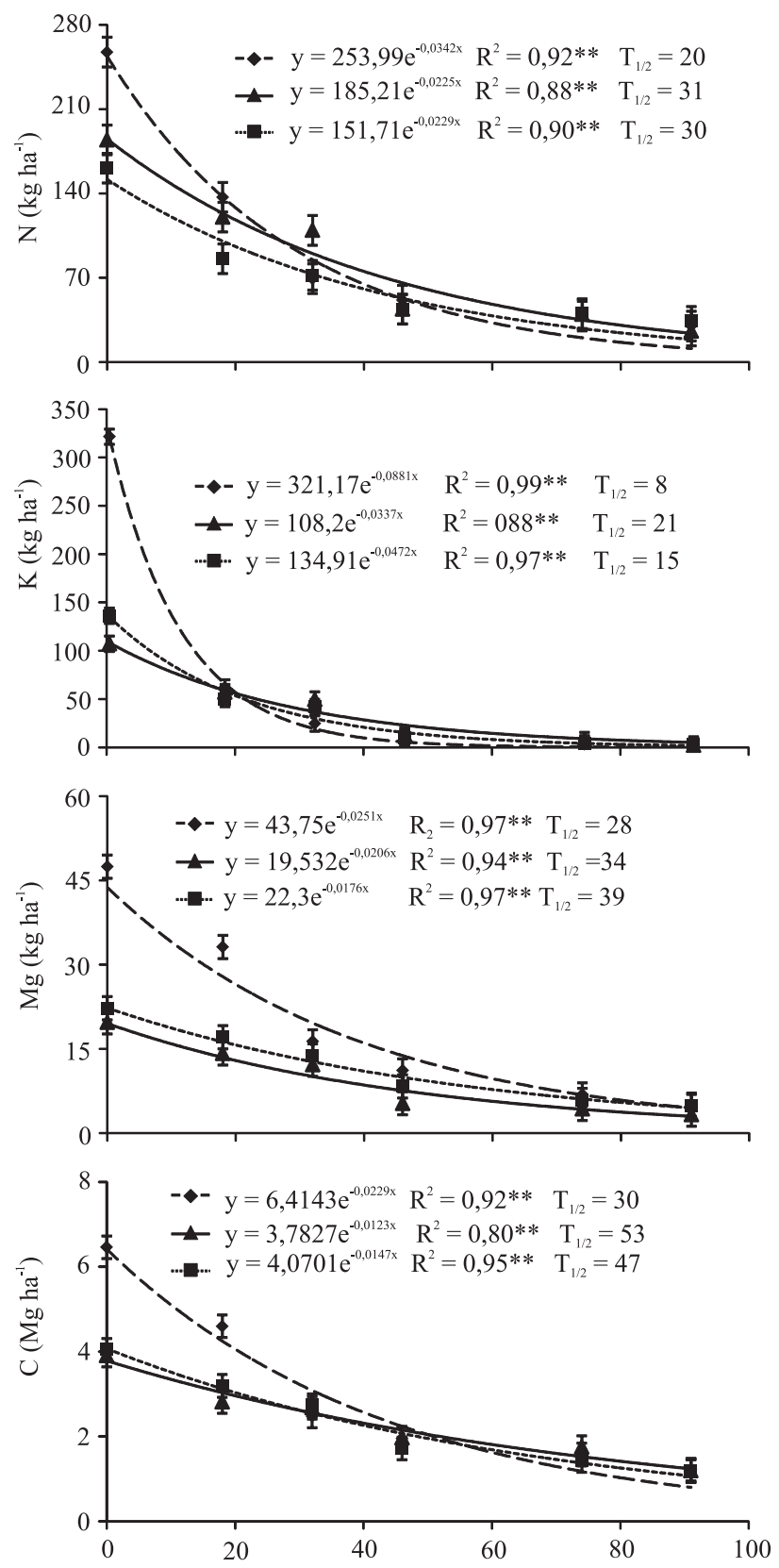

ao solo, aos 120 DAM, cerca de 106, 15, 415, 71, 36 e $16 \mathrm{~kg} \mathrm{ha}^{-1}$, respectivamente. As maiores quantidades obtidas por esses autores deveram-se, provavelmente, ao maior período de avaliação e também à adubação de plantio realizada na semeadura das espécies de cobertura.
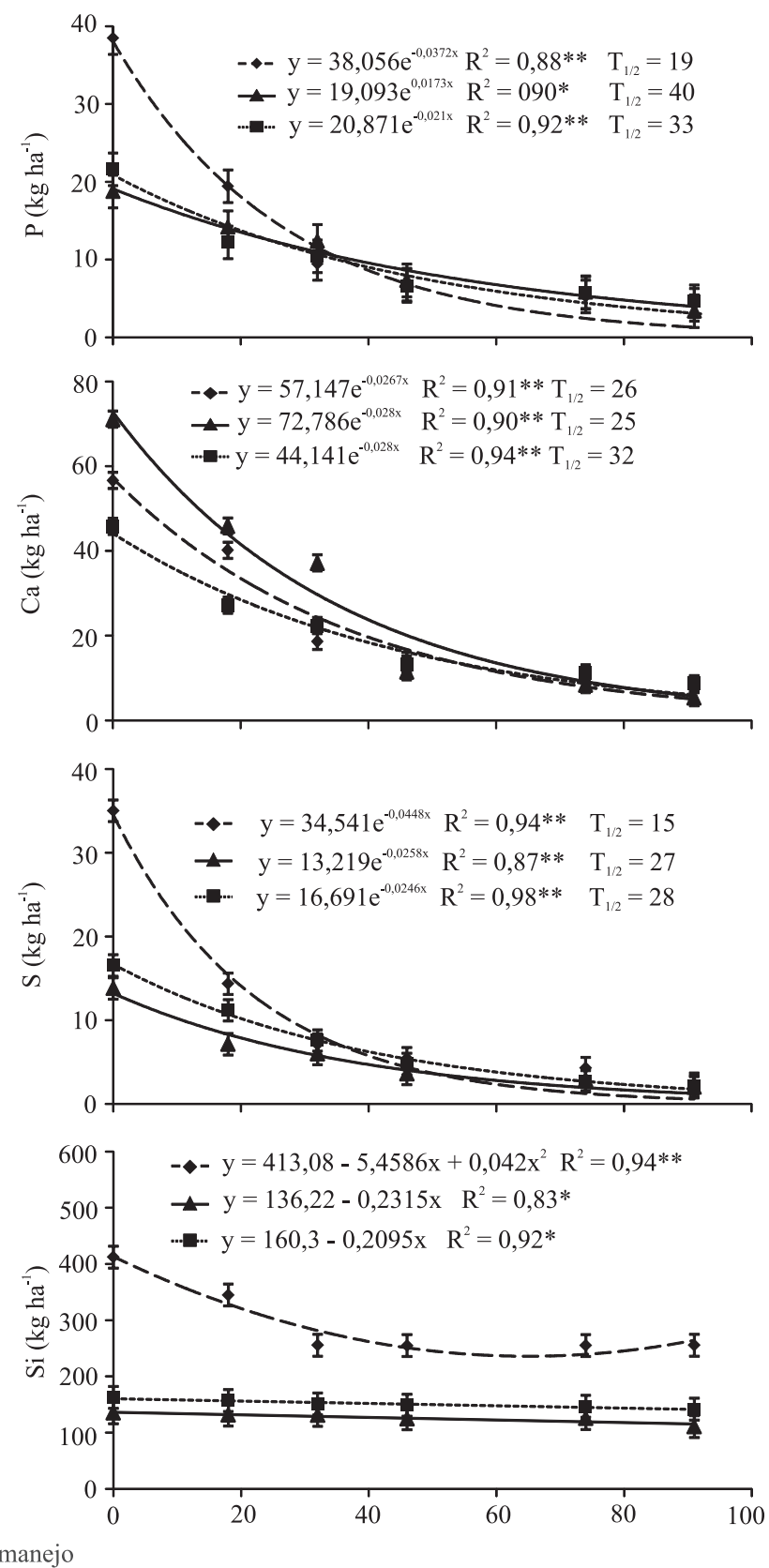

Figura 4. Quantidade remanescente de $\mathrm{N}, \mathrm{P}, \mathrm{K}, \mathrm{Ca}, \mathrm{Mg}, \mathrm{S}, \mathrm{C}$ e Si na matéria seca de milheto (- $\bullet-)$, crotalária ( $₫$ ) e no consórcio (…), em função do tempo após o manejo. ** e *Significativo a 1 e $5 \%$ de probabilidade, respectivamente, pelo teste F. T1/2 refere-se ao tempo de meia vida, em dias após o manejo. Barras verticais indicam o valor de DMS pelo teste de Tukey, a $5 \%$ de probabilidade. 
Pôde-seconstatar, portanto, que porçõessignificativas de nutrientes foram liberadas, que poderiam atender às necessidades da cultura sucessora. Das quantidades totais de N, P, K, Ca, Mg, S e C acumuladas na fitomassa, $50 \%$ foi liberado para o solo pelo milheto até os 20 , $19,8,26,28,15$ e 30 DAM, respectivamente. Para a crotalária, esse valor ocorreu aos 31, 40, 21, 25, 34, 27 e 53 DAM, e, para o consórcio, aos 30, 33, 15, 32, 39, 28 e 47 DAM. Torres et al. (2008), ao estudar a produção e a degradação da fitomassa de milheto e crotalária em cultivo solteiro, constataram que a liberação de 50\% das quantidades totais acumuladas de $\mathrm{N}, \mathrm{P}, \mathrm{Ca}, \mathrm{Mg}$ e $\mathrm{S}$ ocorreu aos 88, 210, 47, 19 e 61 DAM, pelo milheto, e aos $66,267,38,43$ e 69, pela crotalária. A menor taxa de liberação dos nutrientes observada por esses autores possivelmente está relacionada ao menor índice pluvial após o manejo das espécies de cobertura (Boer et al., 2008; Leite et al., 2010).

Observou-se que a maior velocidade de liberação ocorreu entre 0 e 18 DAM (Tabela 1). Portanto, a disponibilização dos nutrientes avaliados ocorre mais rapidamente na fase imediatamente após a dessecação, com redução contínua e posterior tendência à estabilização ao longo do tempo. Crusciol et al. (2008), ao avaliar a taxa de liberação de nutrientes em aveia-preta, observaram maior taxa entre 10 e 20 DAM. Os autores cultivaram a aveia-preta no período de julho a setembro, em um Latossolo Vermelho eutroférrico; dessa forma, é importante destacar a semelhança desses resultados com os deste trabalho, apesar de as condições edafoclimáticas terem sido diferentes.

No período entre 0 e $18 \mathrm{DAM}$, as taxas diárias de liberação de $\mathrm{N}, \mathrm{P}, \mathrm{K}, \mathrm{Ca}, \mathrm{Mg}, \mathrm{S}$ e $\mathrm{C}$ da fitomassa atingiram $6,49,1,03,14,19,1,21,0,88,1,06 \mathrm{e}$ $120 \mathrm{~kg} \mathrm{ha}^{-1}$ por dia no milheto, 3,43, 0,28, 2,73, 1,60, $0,33,0,27$ e $53 \mathrm{~kg} \mathrm{ha}^{-1}$ por dia na crotalária, e 2,85, $0,36,4,29,0,80,0,34,0,33$ e $42 \mathrm{~kg} \mathrm{ha}^{-1}$ por dia no consórcio (Tabela 1). O Si na fitomassa da crotalária e no consórcio teve liberação constante, com média de $0,22 \mathrm{~kg} \mathrm{ha}^{-1}$ por dia durante todo o período avaliado. $\mathrm{Na}$ fitomassa do milheto, no primeiro período avaliado, a taxa diária de liberação do Si atingiu a intensidade de $4,70 \mathrm{~kg} \mathrm{ha}^{-1}$ por dia, e, no último período (91 DAM), já não havia mais liberação de Si (Tabela 1).

A forma, a quantidade e a velocidade com que cada macroelemento foi liberado, independentemente do tipo de cobertura vegetal, permitem inferir que, para maximizar o aproveitamento desses nutrientes, a implantação da cultura principal deve ser realizada após o manejo das plantas de cobertura. Vale ressaltar que o milheto produziu e acumulou as maiores quantidades de fitomassa seca e nutrientes, com exceção do $\mathrm{Ca}$, o que confirma o grande potencial de utilização desta espécie como planta de cobertura para ciclagem de nutrientes. $\mathrm{O}$ uso da crotalária deve ser priorizado em áreas infestadas com nematoides. Já a consorciação, não proporcionou benefícios substanciais em relação às duas espécies cultivadas isoladamente.

\section{Conclusões}

1. O milheto produz maior quantidade de fitomassa e acumula mais $\mathrm{N}, \mathrm{P}, \mathrm{K}, \mathrm{Mg}, \mathrm{S}, \mathrm{C}$ e $\mathrm{Si}$, enquanto a crotálaria acumula maior quantidade de $\mathrm{Ca}$.

2. A fitomassa do milheto apresenta maior taxa de decomposição e de liberação de nutrientes.

3. As maiores taxas de decomposição e de liberação diária de nutrientes das palhadas ocorrem de 0 a 18 dias após o manejo.

4. Com o passar do tempo, ocorre aumento das relações $\mathrm{C} / \mathrm{N}, \mathrm{C} / \mathrm{P}$ e $\mathrm{C} / \mathrm{S}$ e redução da relação $\mathrm{C} / \mathrm{Si}$ e da taxa de decomposição da matéria seca.

5. O Ké o nutriente mais rapidamente disponibilizado ao solo, e o Si apresenta a menor taxa de liberação.

\section{Agradecimentos}

À Fundação de Amparo à Pesquisa do Estado de São Paulo, pelo apoio financeiro; ao Conselho Nacional do Desenvolvimento Científico e Tecnológico, pela concessão de bolsas.

\section{Referências}

BOER, C.A.; ASSIS, R.L. de; SILVA, G.P.; BRAZ, A.J.B.P.; BARROSO, A.L. de L.; CARGNELUTTI FILHO, A.; PIRES, F.R. Biomassa, decomposição e cobertura do solo ocasionada por resíduos culturais de três espécies vegetais na região Centro-Oeste do Brasil. Revista Brasileira de Ciência do Solo, v.32, p.843-851, 2008.

BOER, C.A.; ASSIS, R.L. de; SILVA, G.P.; BRAZ, A.J.B.P.; BARROSO, A.L. de L.; CARGNELUTTI FILHO, A.; PIRES, F.R. Ciclagem de nutrientes por plantas de cobertura na entressafra em um solo de cerrado. Pesquisa Agropecuária Brasileira, v.42, p.1269-1276, 2007.

CRUSCIOL, C.A.C.; MORO, E.; LIMA, E. do V.; ANDREOTTI, M. Taxas de decomposição e de liberação de macronutrientes da palhada de aveia preta em plantio direto. Bragantia, v.67, p.481-489, 2008. 
CRUSCIOL, C.A.C.; SORATTO, R.P. Nitrogen supply for cover crops and effects on peanut grown in succession under a no-till system. Agronomy Journal, v.101, p.40-46, 2009.

CRUSCIOL, C.A.C.; SORATTO, R.P. Nutrição e produtividade do amendoim em sucessão ao cultivo de plantas de cobertura no sistema plantio direto. Pesquisa Agropecuária Brasileira, v.42, p.1553-1560, 2007.

FERNANDEZ, F.A.; BULL, L.T.; CORRÊA, J.C.; CRESPAM, D.R. Influência de silicato e calcário na decomposição de resíduos culturais e disponibilidade de nutrientes ao feijoeiro. Revista Brasileira de Ciência do Solo, v.33, p.935-945, 2009.

GAMA-RODRIGUES, A.C. da; GAMA-RODRIGUES, E.F. da; BRITO, E.C. de. Decomposição e liberação de nutrientes de resíduos culturais de plantas de cobertura em Argissolo Vermelho-Amarelo na região noroeste fluminense-RJ. Revista Brasileira de Ciência do Solo, v.31, p.1421-1428, 2007.

INOMOTO, M.M.; ANTEDOMÊNICO, S.R.; SANTOS, V.P.; SILVA, R.A.; ALMEIDA, G.C. Avaliação em casa de vegetação do uso de sorgo, milheto e crotalária no manejo de Meloidogyne javanica. Tropical Plant Pathology, v.33, p.125-129, 2008.

KHATOUNIAN, C.A. O manejo da fertilidade em sistemas de produção. In: CASTRO FILHO, C. de; MUZILLI, O. (Ed.). Uso e manejo dos solos de baixa aptidão agrícola. Londrina: IAPAR, 1999. p.179-221. (IAPAR. Circular técnica, 108).

KLIEMANN, H.J.; BRAZ, A.J.P.B.; SILVEIRA, P.M. da. Taxas de decomposição de resíduos de espécies de cobertura em Latossolo Vermelho distroférrico. Pesquisa Agropecuária Tropical, v.36, p.21-28, 2006.

KORNDÖRFER, G.H.; PEREIRA, H.S.; CAMARGO, M.S. de. Silicatos de cálcio e magnésio na agricultura. Uberlândia: GPSi/ ICIAG/UFU, 2002. 23p.

LEITE, L.F.C.; FREITAS, R. de C.A.; SAGRILO, S.; GALVÃO, S.R. da S. Decomposição e liberação de nutrientes de resíduos vegetais depositados sobre Latossolo Amarelo no cerrado Maranhense. Revista Ciência Agronômica, v.41, p.29-35, 2010.

MALAVOLTA, E.; VITTI, G.C.; OLIVEIRA, S.A. de. Avaliação do estado nutricional das plantas: princípios e aplicações. Piracicaba: Potafos, 1997. 308p.

MARSCHNER, H. Mineral nutrition of higher plants. Amsterdam: Elsevier; Academic Press, 2012. 684p.

MENEZES, L.A.S.; LEANDRO, W.M.; OLIVEIRA JUNIOR, J.P. de; FERREIRA, A.C.B.; SANTANA, J. das G.; BARROS, R.G. Produção de fitomassa de diferentes espécies, isoladas e consorciadas, com potencial de utilização para cobertura do solo. Bioscience Journal, v.25, p.7-12, 2009.

PACHECO, L.P.; BARBOSA, J.M.; LEANDRO, W.M.; MACHADO, P.L.O. de A.; ASSIS, R.L. de; MADARI, B.E.; PETTER, F.A. Produção e ciclagem de nutrientes por plantas de cobertura nas culturas de arroz de terras altas e de soja. Revista Brasileira de Ciência do Solo, v.35, p.1787-1799, 2011a.
PACHECO, L.P.; LEANDRO, W.M.; MACHADO, P.L.O. de A.; ASSIS, R.L. de; COBUCCI, T.; MADARI, B.E.; PETTER, F.A. Produção de fitomassa e acúmulo e liberação de nutrientes por plantas de cobertura na safrinha. Pesquisa Agropecuária Brasileira, v.46, p.17-25, 2011b.

PAUL, E.A.; CLARK, F.E. Soil microbiology and biochemistry. San Diego: Academic Press, 1989. 275p.

PERIN, A.; GUERRA, J.G.M.; TEIXEIRA, M.G. Cobertura do solo e acumulação de nutrientes pelo amendoim forrageiro. Pesquisa Agropecuária Brasileira, v.38, p.791-796, 2003.

PERIN, A.; SANTOS, R.H.S.; URQUIAGA, S.; GUERRA, J.G.M.; CECON, P.R. Produção de fitomassa, acúmulo de nutrientes e fixação biológica de nitrogênio por adubos verdes em cultivo isolado e consorciado. Pesquisa Agropecuária Brasileira, v.39, p.35-40, 2004.

PERIN, A.; SANTOS, R.H.S.; URQUIAGA CABALLERO, S.S.; GUERRA, J.G.M.; GUSMÃO, L.A. Acúmulo e liberação de P, K, $\mathrm{Ca}$ e $\mathrm{Mg}$ em crotalária e milheto solteiros e consorciados. Revista Ceres, v.57, p.274-281, 2010.

PINILLA, A. Estado actual de los estudios de fitolitos en suelos y planta. Madrid: Centro de Ciencias Medioambientales, 1997. 292p.

ROSOLEM, C.A.; CALONEGO, J.C.; FOLONI, J.S.S. Lixiviação de potássio da palha de espécies de cobertura de solo de acordo com a quantidade de chuva aplicada. Revista Brasileira de Ciência do Solo, v.27, p.355-362, 2003.

SALTON, J.C.; KICHEL, A.N. Milheto: uma alternativa para cobertura do solo e alimentação animal. Revista Plantio Direto, n.45, p.41-43, 1998.

SANTOS, H.G. dos; JACOMINE, P.K.T.; ANJOS, L.H.C. dos; OLIVEIRA, V.A. de; OLIVEIRA, J.B. de; COELHO, M.R.; LUMBRERAS, J.F.; CUNHA, T.J.F. (Ed.). Sistema brasileiro de classificação de solos. 2.ed. Rio de Janeiro: Embrapa Solos, 2006. 306p.

TEDESCO, M.J.; WOLKWEISS, S.J.; BOHNEN, H. Análises de solo, plantas e outros materiais. Porto Alegre: Universidade Federal do Rio Grande do Sul, 1985. 188p.

TEIXEIRA, C.M.; CARVALHO, G.J. de; ANDRADE, M.J.B.A. de; SILVA, C.A.; PEREIRA, J.M. Decomposição e liberação de nutrientes das palhadas de milheto e milheto + crotalária no plantio direto do feijoeiro. Acta Scientiarum. Agronomy, v.31, p.647-653, 2009.

THOMAS, R.J.; ASAKAWA, N.M. Decomposition of leaf litter from tropical forage grasses and legumes. Soil Biology and Biochemistry, v.25, p.1351-1361, 1993.

TORRES, J.L.R; PEREIRA, M.G.; FABIAN, A.J. Produção de fitomassa por plantas de cobertura e mineralização de seus resíduos em plantio direto. Pesquisa Agropecuária Brasileira, v.43, p.421-428, 2008.

WUTKE, E.B. Adubação verde: manejo da fitomassa e espécies utilizadas no Estado de São Paulo. In: WUTKE, E.B.; BULISANE, E.A.; MASCARENHAS, H.A.A. (Coord.). Curso sobre adubação verde no Instituto Agronômico. Campinas: Instituto Agronômico, 1993. p.17-29. (IAC. Documentos, 35).

Recebido em 22 de março de 2012 e aprovado em 3 de setembro de 2012

Pesq. agropec. bras., Brasília, v.47, n.10, p.1462-1470, out. 2012 